Running head: THE CONCEPT OF DISIDENTIFICATION

When group memberships are negative: The concept, measurement and behavioral implications of psychological disidentification

\author{
Julia C. Becker \\ Philipps-University Marburg, Germany
}

Nicole Tausch

University of St Andrews, UK

Author addresses:

Dr. Julia Becker, Philipps-University Marburg, Department of Psychology, Social Psychology,

Gutenbergstraße 18, 35032 Marburg, Germany, e-mail: beckeri2@staff.uni-marburg.de.

Dr. Nicole Tausch, School of Psychology \& Neuroscience, University of St Andrews, St Mary's Quad, South Street, St Andrews, KY16 9JP, Scotland, E-mail: nt20@st-andrews.ac.uk

Tel: +44 (0)1334 462069

Author note:

Correspondence concerning this article should be addressed to Julia Becker, Philipps-University Marburg, Department of Psychology, Social Psychology, Gutenbergstraße 18, 35032 Marburg, Germany, e-mail: beckerj2@staff.uni-marburg.de. This research was conducted while Julia Becker was a visiting researcher at the University of St Andrews. The research fellowship was funded by the German Research Foundation (DFG BE 4648/2-1). We thank Jan Weber for his comments on an earlier version of this paper. 


\begin{abstract}
This research introduces a multi-component model of ingroup disidentification that distinguishes three disidentification components (detachment, dissatisfaction, and dissimilarity). In Studies 1a ( $N=$ $168)$ and $1 b(N=215)$, the authors developed a measurement scale that assesses these components, and examined alternative factorial structures. Study $2(N=115)$ provides evidence that the disidentification scale performs better at distinguishing between disidentification and nonidentification than an established identification scale. Using additional data from Studies $1 \mathrm{~b}$ and 2, Studies $3 a$ and $3 b$ examined emotions and behavioral intentions as correlates of disidentification and revealed that the disidentification components predict negative ingroup-directed behavioral intentions (active harm, passive harm, and passive facilitation) and identity concealment over and above measures of identification. Theoretical implications for research on social stigma and social change are discussed.
\end{abstract}

KEYWORDS: disidentification; disidentification scale; identification; emotions; stigma; BIAS map. 
We belong to a variety of social groups and these group memberships often form important parts of our identity (Tajfel \& Turner, 1979). While many of our group affiliations represent positive aspects of our identity and imbue us with a sense of pride, others are less central and unimportant to us; our membership in these groups is neither particularly satisfying nor dissatisfying. There are some group memberships, however, that are problematic, uncomfortable or even painful (e.g., Levin \& van Laar, 2006); we try to downplay our membership in these groups and even actively distance ourselves from these unwanted identities. For example, people sometimes disidentify from groups that are stigmatized or discriminated against (see Branscombe, Fernández, Gómez \& Cronin, 2011; Major \& O’Brien, 2005), from superordinate groups that reject or marginalize a minority group one belongs to (Jasinskaja-Lahti, Liebkind \& Sohlheim, 2009), or from ingroups that violate personally important moral standards (e.g., Glasford, Pratto, \& Dovidio, 2008). Disidentification is also prevalent among members of disadvantaged groups who have managed to move into higher status positions (e.g., Ellemers, van den Heuvel, de Gilder, Maass \& Bonvini, 2004).

Undoubtedly, disidentification from ingroups is a common and important psychological phenomenon that deserves research attention. Nonetheless, little is yet known about its structure, measurement, correlates, and likely consequences. The present research aims to fill these gaps in the literature. First, we introduce a multi-component model of disidentification that distinguishes three components (detachment, dissatisfaction, and dissimilarity). We then outline how disidentification was defined and measured in prior work and highlight several shortcomings. Next, we distinguish disidentification from nonidentification and identification and explain why we need the concept of disidentification. We then present three empirical studies that develop a threecomponent scale of disidentification, provide evidence that disidentification can be distinguished from nonidentification and demonstrate the unique contribution of disidentification as a predictor of ingroup-directed emotions and behavioral intentions.

\section{The Concept of Disidentification}


Disidentification is a psychological phenomenon that occurs when individuals belong to groups they do not wish to belong to. Thus, disidentification relates to identities that are perceived to be threatening to the self (e.g., Dean, 2008). If individuals cannot physically escape from the group, they create a psychological distance between themselves and the group. The concept of disidentification has been of interest in a number of domains. Nonetheless, prior research is hard to integrate, because little systematic attention has been devoted to the conceptualization of disidentification. Specifically, disidentification research lacks a common understanding of what disidentification is and how it should be assessed. The inconsistent definitions of disidentification resulted in a wide variation in the measurement of the concept, which rendered prior studies largely incomparable. Thus, the first aim of the present work is to develop a unifying conceptualization and measurement instrument of disidentification and its components.

Parallel to three-component conceptualizations of identification (that include an emotional, evaluative and cognitive component, e.g., Ellemers, Kortekaas, \& Ouwerkerk, 1999; Cameron, 2004), we propose that disidentification manifests itself along three dimensions: one's detachment from the group; one's dissatisfaction with the group membership; and one's perceived dissimilarity to other ingroup members. Although these elements have appeared in prior work on disidentification (see below), they were never systematically distinguished. Detachment from an ingroup represents a negative motivational state that ranges from feelings of (rather passive) alienation and estrangement to an active separation from one's ingroup. Although the person is objectively still part of the group, any commitments or psychological ties to the ingroup are severed. Detachment may, for example, occur when the individual perceives a moral conflict with the group, or when the group violates important values (e.g., Glasford et al., 2008). As described by Tajfel (1974), such a conflict can occur when the superior status of one's ingroup comes to be viewed as highly illegitimate and morally unjustifiable, resulting in one's physical and/or psychological exit from the group. The dimension of detachment also featured in prior conceptualizations of disidentification. For instance, disidentification has been defined - among other things - as active/cognitive 
separation (Matschke \& Sassenberg, 2010a; Kreiner \& Ashforth, 2004; Elsbach \& Battacharya, 2001), disengagement (Jasinskaja-Lahti , Liebkind, \& Solheim, 2009), or distancing from the ingroup (Ikegami, 2010; Ikegami \& Ischida, 2007; Verkuyten \& Yildiz, 2007).

Dissatisfaction relates to a negative evaluation of one's group membership. Individuals who are dissatisfied are unhappy about belonging to the group and regret their group membership. Dissatisfaction is related to the perceived respect and esteem one's group receives in society and may be amplified through negative experiences of being discriminated against or rejected (e.g., Levin \& van Laar, 2006). For example, if a woman repeatedly fails to be hired for a leadership position because a male colleague was selected, and attributes this to discrimination, she might become dissatisfied with her group membership. Dissatisfaction can also be found in prior work of disidentification. For instance, disidentification has been defined as negative affect associated with one's unwilling categorization as a group member (Ikegami, 2010; Matschke \& Sassenberg, 2010).

The final dimension we propose is dissimilarity, which is the degree to which individuals perceive themselves as different from the ingroup prototype; i.e., they view themselves as dissimilar to other ingroup members and view themselves as possessing characteristics that are the direct opposites of those of their fellow ingroup members. Dissimilarity might be experienced in particular among members of low-status groups who have successfully entered a higher status group (e.g., Ellemers et al., 2004; Wright \& Taylor, 1998). By entering a domain that is not normally open to ingroup members, the successful tokens present a minority, individuals with special talents, which might motivate them to perceive themselves as dissimilar from other ingroup members. For example, researchers have illustrated that women who have entered a high status masculine domain actively distance themselves from the group stereotype by describing themselves in less feminine and more masculine terms (Ellemers et al., 2004). Dissimilarity can also be found in prior conceptualizations of disidentification. For instance, prior work defined disidentification as the degree to which a person defines him or herself as not having the same attributes as (Elsbach \& Battacharya, 2001) or as being distinct from (Kreiner \& Ashforth, 2004) the group. 
In sum, we define disidentification as a process that ranges from feelings of alienation to an active separation from one's ingroup (detachment), is expressed in feelings of dissatisfaction with one's group membership (dissatisfaction) and in the perception that one is dissimilar to other group members (dissimilarity). Importantly, the group from which the individual disidentifies is part of the self-concept (for a conceptualization of disidentification for individuals external to the group, see Elsbach and Bhattacharya, 2001).

\section{Prior Measurement of Disidentification}

Disidentification has been examined in different lines of research. As noted above, these studies relied on diverse definitions of disidentification that emphasized different components of the phenomenon. Consequently, there are almost as many disidentification scales as disidentification studies. In our review of the existing work we identified four different approaches to assessing disidentification: First, researchers have used qualitative methods to explore the nature of disidentification (e.g., Elsbach, 1999). Second, researchers have used established measures of ingroup identification and interpreted low or reduced levels of identification as indicators of disidentification (e.g., Becker , Tausch, Spears \& Christ, 2011; Glasford et al., 2008; Jasinskaja-Lahti et al., 2009). A problem of this approach is that it remains unclear whether low scores on the identification measure represent disidentification or simply reflect a lack of identification with the group (i.e., nonidentification). Third, some researchers have developed one-dimensional scales of disidentification (e.g., Elsbach \& Bhattacharya, 2001; Kreiner \& Ashforth, 2004; Ikegami \& Ischida, 2007; Josiassen, 2001; Verkuyten \& Yildiz, 2007; Zou, Morris \& Benet-Martinez, 2008). A careful examination of these scales indicates, however, that all of these proposed one-dimensional measures contain more than one dimension of disidentification. For example, the Ikegami \& Ischida (2007) scale contains items measuring dissatisfaction ("I am unhappy that I am a student of XXX") and dissimilarity ("I would feel uncomfortable if I were seen in terms of my membership in XXX"). Moreover, some of these scales include elements that go beyond the scope of disidentification, namely specific emotions (e.g., shame, embarrassment, Ikegami \& Ischida, 2007; Kreiner \& 
Ashforth), attitudes (e.g., "This organization does shameful things", Kreiner \& Ashforth, 2004), and behaviors (e.g., "I always tend to not shop in the same places as the Dutch", Josiassen, 2011). Accordingly, these scales are not comparable across studies and assess different manifestations of disidentification, leaving the nature of the construct unclear. The fourth and final approach to measuring disidentification is the multi-component approach. To our knowledge, this approach has thus far been used in just one series of studies (Matschke \& Sassenberg, 2010a, 2010b). In their comprehensive work, Matschke and Sassenberg distinguished three facets: exit (e.g., "I am thinking about leaving the group"), recategorization ("I tell myself I have a number of other groups in which I can play a part"), and bad feeling ("I feel bad when I meet this group"). However, based on our definition of disidentification outlined above, only the last component taps a core element of disidentification (dissatisfaction), whereas exit presents a behavioral intention to leave the group, and recategorization presents a coping strategy to re-establish positive distinctiveness. Taken together, although all of the existing disidentification scales have their merits, the main pitfall of these measurement instruments is that they do not capture disidentification unambiguously. Below we explain why disidentification is distinct from nonidentification and does not simply present the opposite pole to identification on a bipolar scale.

\section{How Disidentification Differs from Nonidentification and Identification}

Despite the different conceptualizations of disidentification, many authors agree that disidentification needs to be distinguished from nonidentification, because it presents a unique psychological state (e.g., Elsbach, 1999; Ikegami, 2010; Ikegami, 2010; Jasinskaja-Lahti et al., 2009; Long \& Spears, 1997; Verkuyten \& Yildiz, 2007, ). As described above, disidentification involves disconnecting (typically negative) aspects of the group from the self, separating one's identity from the group, feeling dissatisfied about belonging to the group and perceiving oneself as different from other group members. In contrast, nonidentification with a group is a rather neutral process which is characterized by a lack of both identification and disidentification (Elsbach, 1999). Thus, nonidentification occurs when a person neither connects nor separates his or her identity from the 
group (Elsbach \& Bhattacharya, 2001). Accordingly, non-identifiers do not have any affective investment in an antagonistic relation, but simply do not care about the group, neither in a positive nor in a negative way (e.g., Dean, 2008). Consistent with this idea, there is some evidence that disidentification and nonidentification differ in terms of their predictors (Kreiner \& Ashforth, 2004) and outgroup-directed behavioral intentions (Ikegami \& Ischida, 2007). Prior research did not, however, examine the distinction between disidentification and nonidentification in terms of ingroup-directed behavioral intentions, nor whether disidentification measures perform better in distinguishing between disidentification and nonidentification than identification measures. In the present research, we will investigate the distinction between disidentification and nonidentification more systematically. In addition, we argue that disidentification is not merely the opposite of identification, but contributes to our understanding of social-psychological processes above and beyond identification. Specifically, we assume that the absence of disidentification does not equal being more identified with the group and thus, should not predict ingroup-supporting behaviors. Similarly, the absence of identification does not equal being more disidentified from the group and thus should not predict ingroup-harming behaviors. Accordingly, identification and disidentification should have different causes and consequences. This assumption is in line with prior findings that positive and negative motivational states constitute separate dimensions with different psychological correlates and outcomes. For example, Watson, Clark and Tellegen (1988) demonstrated that positive and negative affect are two independent dimensions of emotionality that uniquely predict social activity and perceived stress, respectively. Similarly, Cacioppo, Gardner and Berntson (1997) demonstrated that separate processes underlie the evaluation of the positive and negative aspects of an attitude object. Furthermore, research on self-regulation illustrated that a lack of avoidance motivation does not have the same outcomes as an approach orientation (Elliot, Gable \& Mapes, 2006) and that effects of approach and avoidance motivation on outcome variables are mediated by different processes (Gable, 2006). Moreover, a promotion focus was shown to lead to social discrimination when positive (but not negative) resources had to be allocated, whereas a 
prevention focus led to social discrimination when negative (but not positive) resources were allocated (Sassenberg, Kessler \& Mummendey, 2003).

In line with this general principle, we predict that identification and disidentification differentially predict ingroup-directed behavioral intentions (and corresponding emotions). Identification, as a positive motivational state, should predict positive (but not negative) ingroupdirected behavioral intentions, whereas disidentification, as a negative motivational state, should predict negative (but not positive) ingroup-directed behavioral intentions. This finding would underline the need for the construct of disidentification because it would help us to understand the intriguing question of when and why individuals intend to engage in behaviors that harm a group they belong to.

\section{The Present Research}

We identified three likely components of ingroup disidentification: detachment, dissatisfaction, and dissimilarity. Study 1a documents the development of a multi-component measure designed to assess these three components. In Study 1b, we cross-validated our model in another language. These studies further examined the relationships between disidentification and identification. Moreover, we explored the relations with other potentially linked concepts, specifically interindividual differences in the chronic sensitivity to being stigmatized (stigma consciousness, Pinel, 1999), in the awareness of others' evaluation of one's group (public collective self-esteem, Luhtanen \& Crocker, 1992) and in a negative self-related view (personal self-esteem, e.g., Rosenberg, 1965). In addition, as further validation, we correlated the disidentification scales with an expanded "inclusion of ingroup in the self" measure (Tropp \& Wright, 2001). We designed this "inclusion-exclusion of ingroup from the self"-measure (see Figure 1) to illustrate disidentification pictorially. We expected all disidentification components, but particularly detachment (because it best captures the psychological separation from one's group) to be positively correlated with this measure. The purpose of Study 2 was to demonstrate the usefulness of the multi-component measure of disidentification by testing the hypothesis that the 
disidentification components (but not established components of identification) can distinguish between disidentification and nonidentification. Finally, using additional data collected as part of Studies $1 \mathrm{a}$ and 2 , Studies $3 \mathrm{a}$ and $3 \mathrm{~b}$, we investigate the relation between disidentification and ingroup-directed behavioral tendencies. We test the hypothesis that negative ingroup-directed behavioural intentions can be better predicted by high levels of disidentification than low levels of identification and that this relation is mediated by negative emotions, whereas positive ingroupdirected behavioral intentions can be better predicted by high levels of identification than low levels of disidentification (mediated by positive emotions).

\section{Study 1: Scale Development and Cross-Validation}

Study 1a was conducted for scale development using an English-speaking sample, Study 1b aimed to cross-validate the three-component model of disidentification in a different cultural and language context (Germany).

Method. Participants. Participants of Study 1a were students at a British University ( $N=$ 227); participants of Study $1 \mathrm{~b}$ were students at a German University as well as non-students $(N=$ 411). Students were contacted via a research participation system (Study 1a) and student emaildistribution lists (Study 1b), non-students were contacted via an advertisement in a local online newspaper. The students received course credit while non-students were entered into a $3 \times 20$ EUR prize draw. Eighty-one per cent of the non-students had a high school degree (Abitur) and a further $14 \%$ a university degree. The majority of participants indicated that they belonged to a group from which they disidentified ( $N=168$ in Study $1 \mathrm{a}, N=215$ in Study $1 \mathrm{~b})$. The remaining participants ( $N=$ 59 in Study 1a, N= 196 in Study 1b) were deleted from the sample. The final sample of Study 1a (78\% female) consisted of people from Britain (72), North America (25), Asia (20, e.g., China, India), Western Europe (16, e.g., France, Germany), Eastern Europe (7, e.g., Bulgaria, Poland), Australia (2) and with other or mixed nationalities (8). Most participants of the final sample of Study $1 \mathrm{~b}$ (73\% female) were Germans (91\%); non-Germans came from Southern- or Eastern European countries (e.g., Italy, Bulgaria), three had a dual citizenship, and two came from China. Participants' ages 
ranged from 18 to 66 years (Study $1 \mathrm{a}, M=21.26, S D=2.83$ ) and 18 to 74 years (Study $1 \mathrm{~b}, M=24, S D$ $=8.97)$.

Procedure. Participants received a link to this web-based study, which was announced as a study about "social groups and group memberships". They first read a short introduction explaining that everybody belongs to different social groups and that the current study is about groups people don't like to belong to and from which they would like to distance themselves. Participants were asked whether they personally belonged to such a group. If they could not think of a group, they were asked to imagine belonging to such a group (these participants received credit but were deleted from the sample). All participants were asked to write down the group they were thinking about and to focus on this particular group while completing the entire questionnaire. Participants in both samples disidentified from diverse groups (e.g., working class, private school background, physical stigma, heavyweight, psychological disorder, women, Lesbian Gay Bisexual Transgender [LGBT] people, family, being an immigrant, religion, upper class, students). To further ensure that they thought about the same group at all times, participants were asked to enter the name of the group on the top of each page. Participants completed the measures and validation scales in the order presented below. The disidentification and identification measures were presented in a counterbalanced order. Items for each scale were randomized. Finally, participants were thanked and debriefed.

Measures. All responses were measured on 1 (strongly disagree) to 7 (strongly agree) Likert scales. Alphas before the slash refer to Study $1 \mathrm{a}$, alphas after the slash refer to Study $1 \mathrm{~b}$. In Study $1 \mathrm{~b}$, we included further measures, which are reported in Study $3 a$.

Inclusion-exclusion of ingroup from the self. We expanded the pictorial measure "inclusion of ingroup in the self" (Tropp \& Wright, 2001 ) / "individual ingroup overlap" (Schubert \& Otten, 2002) / "identity fusion" (e.g., Swann, Gómez, Seyle, Morales \& Huici, 2009) to a measure "inclusionexclusion of ingroup from the self" by adding four circles that represent various levels of distance between the self and the group (circles 7-10 in Figure 1). Thus, participants were provided with 10 
pairs of circles, the white circle (yellow in the colored version) represented themselves and the black circle (blue in the colored version) the group they were thinking about. They were asked to select the number that best represents how close to, or distant from this group they felt.

Disidentification. Rather than using the items developed in previous research, which were confounded with attitudes, specific emotions and behaviors, we used Leach et al.'s (2008) scale as an orientation in our scale development. This allowed us to develop purer measures of disidentification. Detachment ( $\alpha=.83 / .75$ based on three items, see below), dissimilarity $\alpha=$ $.84 / .82$ ), and dissatisfaction ( $\alpha=.82 / .84$ ) were measured with four items each (see Appendix). Identification. Identification was measured using Leach et al.'s (2008) five component measure, because the contents of three scales (solidarity, satisfaction, and self-stereotyping) have parallels in the dimensions of detachment, dissatisfaction, and dissimilarity that we identified as central to disidentification above. Three items measured solidarity (e.g., "I feel a bond with this group" $\alpha=.79 / .71$ ), four items assessed satisfaction ("I am glad to be in this group", $\alpha=.80 / .85$ ), two items measured self-stereotyping ("I am similar to the average person in this group", $\alpha=$ $.91 / .87)$. Leach et al. (2008) identified two additional components that do not have direct counterparts in the disidentification literature: three items measured centrality (e.g., "Being a member of this group is an important part of how I see myself"; but the item "I often think about the fact that I am a member of this group" was deleted to improve reliability, $\alpha=.75 / .82$ ), and two items measured homogeneity ("Members of this group are very similar to each other", $\alpha=.86 / .81$ ).

Stigma Consciousness. We used six items of the Stigma Consciousness Scale (Pinel, 1999, e.g., "When interacting with members of other groups, I feel like they interpret all my behaviors in terms of the fact that I am a member of this group", $\alpha=.74 / .68)$.

Public Collective Self-Esteem was measured with the four item scale of Luhtanen and Crocker (1992 e.g., "Overall, this group is considered good by others"; $\alpha=84 / .85$ ). 
Personal Self-Esteem was assessed with three items from the Rosenberg (1965) self-esteem measure (i.e., "On the whole, I am satisfied with myself", "I feel that I have a number of good qualities", "I feel I do not have much to be proud of"[reverse-scored], $\alpha=.80 / .80$ ).

Results. Scale Development and Competing Measurement Models (Study 1a). In order to examine how well our proposed measurement model fit the data, we performed confirmatory factor analyses (CFAs) using Mplus 5.1. Following Leach et al.'s (2008) procedure, items were permitted to load only on the component they were expected to load on and item errors were not allowed to correlate. The three-factor model fit the data well (see Table 1). Results showed that all items loaded on their respective factor with factor loadings $>.68$, with the exception of one item, which loaded poorly (.36). Thus, we decided to exclude this item from the scale. A second CFA based on the remaining 11 items showed a good fit to the data (see Table 1). All fit indicators of our 11-item model exceeded the benchmarks (Hu \& Bentler, 1999) and the AIC indicated that our improved 11item model showed a better fit than the previous 12-item model.

We tested three further alternative models (see Table 1). As noted in the introduction, disidentification is most often measured as a single, one-dimensional factor. Accordingly, the first alternative model specified all items as indicating a general factor of ingroup disidentification. This one component model fit the data poorly and significantly worse than our improved threecomponent model. A second alternative model specified the items of detachment and dissatisfaction as one factor (parallel to an affective ties/social identity factor of identification proposed by Ellemers et al., 1999; see also Jackson, 2002) and dissimilarity as separate factor (parallel to a cognitive/selfcategorization factor of identification in models by Ellemers et al., 1999; Jackson, 2002). This twocomponent model did not fit the data well and represents the data significantly worse than our improved three-component model. A third alternative model specified the items of detachment and dissimilarity as indicating an ingroup distance factor (parallel to Cameron's, 2004, ingroup ties factor of identification) and dissatisfaction as separate factor. Again, this model did not fit the data as well as our three-component model. Thus, our proposed three factor model of disidentification showed 
the best fit to the data.

Finally, we conducted a CFA to test whether a model with three disidentification components and five identification components fits the data better than a five component model in which the three disidentification components load together with their identification parallels. That is, the first model is composed of eight separable factors (three disidentification and five identification components), while the second model is composed of the following five factors: a) detachment and solidarity, b) dissatisfaction and satisfaction, c) dissimilarity and self-stereotyping, d) centrality, and e) homogeneity. Results show that the first model, in which the disidentification and identification components load on separate factors, fits the data better ( $C F I=.95 ; \mathrm{RMSEA}=.05$; SRMR $\left.=.06 ; A I C=13655.10 ; \chi^{2}(247)=346.89\right)$ than the second model in which the disidentification and identification components load together $\left(\mathrm{CFI}=.79 ; \mathrm{RMSEA}=.09 ; \mathrm{SRMR}=.09 ; \mathrm{AIC}=13936.17 ; \chi^{2}\right.$ $(266)=649.05)$. Thus, the data support the idea that disidentification differs from identification and is not the same as low identification.

Cross-Validation (Study 1b). Replicating results from Study 1a, the 11-item three-factor model showed a good fit to the data and a better fit than all alternative models (see Table 1). Moreover, also replicating results from Study 1a, two CFAs revealed that the model in which the disidentification and identification components load on separate factors fits the data better (CFI = $.91 ; \mathrm{RMSEA}=.06 ;$ SRMR $\left.=.07 ; \mathrm{AIC}=18046.56 ; \chi^{2}(248)=441.64\right)$ than the model in which the disidentification and identification components load together (CFI = .80; RMSEA = .09; SRMR = .09; AIC $\left.=18315.33 ; \chi^{2}(266)=723.93\right)$. The residual variance of one item had to be constrained to zero in order to run this analysis.

Intercorrelations (Study $1 a$ before the slash, Study $1 b$ after the slash). Correlations among the disidentification and identification components are depicted in Table 2. Detachment was moderately positively correlated with dissatisfaction $(r=.29 / .17)$ and highly positively correlated with dissimilarity $(r=.56 / .68)$. Dissimilarity and dissatisfaction were also positively correlated $(r=$ $.22 / .12)$. Moreover, detachment and dissimilarity were moderately to highly negatively correlated 
with all identification components ( $r=-.30$ to-.64/-.16 to -.66 ) except homogeneity. Dissatisfaction was negatively correlated with centrality $(r=-.26 /-.13)$, solidarity $(r=-.51 /-.30)$ and satisfaction $(r=-$ $.68 /-.65)$. The pictorial "inclusion-exclusion of ingroup from the self" measure was positively correlated with all disidentification components ( $r=.25$ to $.51 / .13$ to .49$)$ and negatively with all identification components ( $r=-.31$ to $-.35 /-.25$ to -.46$)$, except homogeneity. Moreover, we examined correlations between disidentification and stigma consciousness, public collective selfesteem (PCSE) and personal self-esteem. Correlations with the disidentification components were non-significant except for the following correlations: The higher dissatisfaction, the lower participant's personal self-esteem $(r=-.34, p<.001 / r=-.13, p=.08)$, the lower their PCSE $(r=-.20, p$ $=.01 / r=-.34, p<.001)$ and the higher their stigma consciousness in Study $1 b(r=.20, p<.01)$. Moreover, in Study 1b, stigma consciousness was negatively associated with detachment $(r=-.19, p$ $<.01)$ and dissimilarity $(r=-.19, p<.01)$.

Discussion. Results of Studies 1a and 1b supported the proposed model of disidentification consisting of the three components detachment, dissatisfaction, and dissimilarity. Results revealed that our three-component model fit the data better than plausible alternative one- and twocomponent models in both samples. This is a particular strength, because the model was tested in two different cultural and language contexts. The correlations with our "inclusion-exclusion of ingroup from the self" measure indicated that detachment showed the strongest correspondence with individual-ingroup distance, indicating that the more people feel detached from their group, the bigger the perceived psychological distance between themselves and their group. In line with our hypotheses, the correlations among the disidentification and identification components were moderate and negative. This is in line with previous findings (e.g., Kreiner \& Ashforth, 2004; Matschke \& Sassenberg, 2010b). A CFA revealed that a model with separate identification and disidentification components fits the data better than a model in which identification and disidentification components load together. In addition, although there were some reasonable correlations among disidentification and stigma consciousness, PCSE and self-esteem, these were 
low to moderate in degree. Together, these findings support the idea that the disidentification components are unique and separate constructs. However, it is often the case that positively and negatively coded items load on separate factors. This is why we examined the distinction between identification, nonidentification and disidentification in more detail in Studies 2 and 3. Furthermore, it could be argued that our relatively small sample sizes in Studies $1 \mathrm{a}$ and $1 \mathrm{~b}$ in combination with the relatively complex model might have resulted in under- or overestimation of parameter estimates and standard errors (Herzog, Boomsma, \& Reinecke, 2007; Muthén \& Muthén, 2002). To assess this potential bias, we conducted two Monte Carlo simulations for our proposed measurement model for both Studies 1a and 1b (Muthén \& Muthén, 2002). In each simulation, the parameter values estimated from our data served as the population parameter values. Based on 10,000 replications, we calculated the percentage of bias in the parameter estimates and standard errors (Muthén \& Muthén, 2002). Results of the Monte Carlo simulation show that the bias in parameter estimates $\left(\mathrm{M}_{\text {percentage of bias }}=.70, \mathrm{SD}=.14, \mathrm{Min}=.43, \mathrm{Max}=.94\right)$ and standard errors $\left(\mathrm{M}_{\text {percentage of bias }}=-1.40, \mathrm{SD}\right.$ $=.73, \operatorname{Min}=-2.60, \operatorname{Max}=-.01)$ was very small in both samples. Thus, we can conclude that our measurement model is robust.

\section{Study 2: Distinguishing Disidentification from Nonidentification}

Study 2 aimed to establish that disidentification and nonidentification are different from each other and that our proposed disidentification scale would perform better in distinguishing between disidentification and nonidentification than identification measures. To examine this hypothesis, we conducted an experiment in which participants were asked to think about either an ingroup from which they would like to distance themselves (disidentification), an ingroup they did not really care about belonging to (nonidentification), or an ingroup which they liked belonging to (identification).

Afterwards, participants completed the disidentification and identification scales. If the disidentification components but not the identification components are able to distinguish between disidentification and nonidentification, this would provide further evidence for the usefulness of our 
scale and as additional validation. Specifically, we predicted that participants in the disidentification condition ("disidentifiers") would score significantly higher on ingroup detachment, dissatisfaction, and dissimilarity compared to participants in the nonidentification condition ("non-identifiers"). In contrast, we expected only a small or no difference between non-identifiers and disidentifiers in terms of the three identification components solidarity, centrality, and self-stereotyping because non-identifiers as well as disidentifiers should lack feelings of solidarity, should not engage in selfstereotyping and may both perceive this group to be less central to their self-concept. However, given that disidentification is accompanied by a strong negative evaluation of the ingroup, whereas nonidentification is rather neutral, and should not be accompanied by the same degree of negative emotions, we expected disidentifiers to show a stronger lack of satisfaction compared to nonidentifiers. We examined the difference between identification and the other two conditions for exploratory purposes.

Method. Participants. Participants were 115 students at a German University who were provided with credit points in exchange for their participation. Seventeen participants (14\%; five in the nonidentification condition, two in the identification condition, and ten in the disidentification condition) indicated that they did not belong to such a group and were therefore excluded from the sample. Most participants of the remaining sample ( $N=98,86 \%$ female) were Germans $(92 \%), 8 \%$ came from other European or Asian countries. Participants' ages ranged from 19 to 50 years, with a mean age of 23.39 years $(S D=4.85)$.

Design and Procedure. Participants received the link to this web-based experiment via the email-distribution list of the Psychology department. They first read a short introduction explaining that everybody belongs to a number of social groups and that the extent to which one feels a bond to these groups vary. Participants were presented with a scale to illustrate this variation. They were told that individuals can have a very strong positive emotional bond with their group ("+7"), their group membership can have no emotional meaning for individuals ("0"; the group does neither present something positive nor negative), or individuals can feel an emotional distance to their 
group ("-7"). Following this explanation, participants were randomly assigned to one of three experimental conditions. In the disidentification condition they were asked to think about a group they belong to for which their membership is rather uncomfortable and from which they would like to distance themselves, or that they would like to leave. In the nonidentification condition they were asked to think about a group they belong to for which the group membership is neither particularly comfortable nor uncomfortable and that they do not really care about belonging to. In the identification condition they were asked to think about a group they belong to for which their membership is comfortable; a group that they have a strong bond to and do not want to leave.

As an additional graphic illustration, participants were provided with the above mentioned rating scale ranging from -7 (strong emotional distance), to 0 (nonidentification) to +7 (strong emotional bond). Depending on the condition, either the "-7" (disidentification), the " 0 " (nonidentification), or the " +7 " (identification) were ticked. If students did not belong to a group they were asked to think about, they were instructed to imagine that they would belong to such a group (these participants received credit but were deleted from the sample). Participants in the disidentification condition named groups such as low socio-economic status, women, nationality, religion, students, physical disability, or psychological disorder. Participants in the nonidentification condition named groups such as students, blondes/brunettes, age group, women/men, Germans, work group, or middle class. Participants in the identification condition named groups such as students, sport groups, or national group.

Measures. We used the same measures of "inclusion-exclusion of ingroup from the self", disidentification (detachment, $\alpha=.84$, dissatisfaction, $\alpha=.92$, dissimilarity, $\alpha=.87$ ) and identification (solidarity, $\alpha=.86$, satisfaction, $\alpha=.94$, centrality, $\alpha=.93$, self-stereotyping, $\alpha=.93$, homogeneity, $\alpha$ $=.75$ ) as in the previous studies. Further measures are reported in Study 3b.

Results. As a preliminary result and manipulation check, an ANOVA revealed that participants in the disidentification condition showed the greatest exclusion of the ingroup from the self $(M=6.50, S D=2.13)$ compared to the neutral condition $(M=5.20, S D=1.97)$ and the 
identification condition $(M=3.06, S D=2.03), F(2,95)=23.04, p<.001$, partia $^{2} \eta^{2}=.33$ (all post-hoc tests (Tukey) were significant $p s<.03$ ). To test for differences between the three experimental conditions on the disidentification and identification scales, we conducted a multivariate analysis of variance (MANOVA) with condition (disidentification, nonidentification, identification) as a betweensubject factor and the three disidentification and five disidentification scales as dependent variables. Results revealed a significant effect of condition (Wilks Lamda), $F(16,176)=10.33, p<.001$, partial $\eta^{2}$ $=.48$. At the univariate level, this effect was significant for all nine dependent measures, $F s(2,95)>$ 7.93, $p \mathrm{~s}<.01$, partial $\eta \mathrm{s}^{2}>.14$. Post hoc tests (Tukey) indicated that, as expected, disidentifiers felt more detached from their group, experienced more dissatisfaction, and felt more dissimilar to their group compared to non-identifiers (see Table 3). Moreover, in line with hypotheses, disidentifiers did not differ from non-identifiers in terms of the identification components solidarity, centrality and self-stereotyping. However, as expected, non-identifiers showed higher levels of satisfaction compared to disidentifiers. Finally, disidentifiers as well as identifiers perceived their ingroup to be more homogenous compared to non-identifiers (see Table 3). Results further showed that identifiers scored higher on all five identification components and had lower scores on all three disidentification components compared to both non-identifiers and disidentifiers (see Table 3).

Discussion. This experiment provides evidence that disidentification and nonidentification are distinguishable. Results show that, as expected, disidentifiers scored significantly higher on the three disidentification components compared to non-identifiers: Disidentifiers felt more detached from their group, were more dissatisfied with their group membership, and were more likely to perceive themselves as dissimilar to the group. Importantly, disidentifiers were not distinguishable from non-identifiers in terms of the three identification scales solidarity, centrality and dissimilarity. This demonstrates most clearly the importance of assessing disidentification specifically and independently from identification, and shows the empirical value of our disidentification scale. However, as predicted, disidentifiers were less satisfied with their group membership compared to non-identifiers. 
Moreover, both identifiers and disidentifiers perceived their fellow group members to be more homogenous compared to non-identifiers. This intriguing finding demonstrates that a perception of the ingroup as homogenous might be used strategically by both identifiers and disidentifiers: Previous research has illustrated that high identifiers are inclined to perceive their ingroup as homogenous because they aim to minimize intragroup difference and to maximize intergroup differences (e.g., Turner et al., 1987). Similarly, disidentifiers may find it easier to distance themselves from the ingroup and to perceive themselves as dissimilar to other ingroup members if other ingroup members are viewed as a homogenous entity. However, results of Studies $1 \mathrm{a}$ and $1 \mathrm{~b}$ revealed that homogeneity is unrelated to all disidentification components. Thus, perceiving other group members as homogenous might be one out of several coping strategies associated with disidentification. Finally, exploratory analyses indicated that identifiers had higher scores on all five identification components and lower scores on all three disidentification components compared to disidentifiers and non-identifiers.

\section{Study 3: Emotions and Behavioral Intentions as Correlates of Disidentification}

Using additional data collected as part of Studies $1 \mathrm{~b}$ and 2, the present study aims to contribute to our understanding of the social psychological outcomes of disidentification by examining its unique emotional and behavioral correlates. Further empirical value of the multicomponent measure of disidentification would be shown if the three components predicted self- and ingroup-directed emotions and behavioral intentions over and above measures of ingroup identification. Prior research illustrated that if people disidentify from an organization they do not belong to, they have a stronger intention to publicly criticize this outgroup or to engage in counter-organizational actions (Elsbach \& Battacharya, 2001). However, relations between disidentification and ingroup-directed behaviors have not been studied so far. To distinguish different types of behavioral tendencies we employed Cuddy, Fiske and Glick's (2007) Behaviors from Intergroup Affect and Stereotypes (BIAS) map framework, according to which behaviors can be distinguished in terms of their intensity (active vs. passive) and valence (harm vs. facilitation). This distinction results in four types of 
behavior: active harm, active facilitation, passive harm and passive facilitation. Active harm refers to negatively valenced behaviors that aim to harm the target group directly ("acting against", e.g., verbal or violent attacks). Passive harm refers to behaviors that harm the target group less directly ("acting without" the target, e.g., ignoring the target group). Active facilitation refers to positively valenced behaviors that provide direct help or assistance ("acting for"). Passive facilitation means "acting with" the target group in order to achieve personal benefits. Thus, the ostensibly positive aspect of passive facilitation for the target group is not intended (friendly relationships with this group are not desired), but a mere by-product of using the group to achieve personal goals. Therefore, passive facilitation can be perceived as a negative behavior as well. To our knowledge, these behavioral tendencies have been solely examined in relation to outgroups (e.g., Cuddy et al., 2007); the current research is thus the first to apply this framework to behaviors directed at ingroups. We consider an additional, fifth form of behavior from the stigma literature that is not part of the BIAS map but seems to be important in the context of disidentification, namely identity concealment (e.g., Barreto, Ellemers, \& Banal, 2006; Quinn, 2006), which involves behaviors like hiding one's stigmatized identity.

Consistent with prior work demonstrating that positive and negative motivational states have distinct causes and consequences (e.g., Cacioppo et al., 1997; Gable \& Strachman, 2008; Sassenberg et al., 2003; Watson et al., 1988), we argue that disidentification is not merely the opposite of identification but predicts different psychological outcomes. Thus, we expect that the extent to which these five behavioral tendencies are present, varies as a function of the three facets of disidentification. Specifically, we expected that negative ingroup-directed behavioral intentions (active and passive harm, passive facilitation) can be predicted by disidentification but not identification, whereas positive ingroup-directed behavioral intentions (active facilitation) can be predicted by identification but not disidentification. Moreover, we expected that detachment plays a major role in predicting negative ingroup-directed behavioral intentions. While identification, solidarity and psychological ingroup ties serve to uphold cooperative interdependence in groups 
(e.g., Brewer, 2001), psychological detachment can provide the basis for negative behaviors towards the ingroup. As described above, detachment likely happens when an individual perceives a moral conflict with the ingroup, the ingroup becomes an obstacle of one's goals, and represents a negative aspect of the self (Tajfel, 1974), such as when the group violates personal values or has a morally unjustifiable advantage. In such cases, a motivation to directly and indirectly harm the group seems likely. In contrast, although disidentification should be negatively correlated with positive ingroupdirected behavioral intentions, it is likely that identification is a better predictor of positive ingroupdirected behavioral intentions (i.e., active facilitation). Finally, the intention to hide a stigma (identity concealment) is a coping response to prevent stigma-based ostracism (e.g., Barreto et al., 2006; Quinn, 2006) and should be positively associated with disidentification. Specifically, we expect that people try to conceal belonging to a specific group particularly when they are dissatisfied with their group membership.

Moreover, we also explored whether the extent to which the relations between the disidentification components and different behavioral intentions are mediated by emotions experienced towards the ingroup. We examined ingroup-directed emotions (such as admiration, anger and contempt) and self-directed emotions (shame, guilt). First, we expected that the positive relation between disidentification and negative ingroup-directed behavioral intentions (active harm, passive harm, passive facilitation) would be mediated by negative ingroup-directed emotions. Disidentifiers should intend to attack their group, ignore their group and use the group for egoistic purposes because they experience negative emotions like anger, hate and contempt toward this group. Secondly, given that identity concealment is a self-related rather than ingroup-related behavior, we expected that the positive relation between disidentification and the intention for identity concealment would be mediated by negative self-directed emotions, namely feelings of shame. Finally, according to the BIAS map, positive ingroup-directed behaviors can be predicted by positive emotions (e.g., admiration, Cuddy et al., 2007). We thus expected the relation between 
identification and positive ingroup-directed behavioral intentions (active facilitation) to be mediated by positive emotions.

\section{Study 3a}

Method. Measures. Data for the present study were collected as part of Study 1b. In addition to the identification and disidentification measures, this study included measures of emotions and action tendencies.

Emotions. Negative emotions were measured with six items ("I'm angry with / I'm annoyed with / I hate / I'm disgusted by / I feel contempt for/ I detest... this group", $\alpha=.89$ ); positive emotions were measured with three items ("I admire this group/ This group makes me happy/ I respect this group", $\alpha=.68$ ); shame was measured with three items ("I feel embarrassed / I feel ashamed for this group/ I'm ashamed for belonging to this group", $\alpha=.79$ ). We also included two items measuring guilt for exploratory purposes ("I feel guilty on behalf of / I feel guilty about belonging to this group", $\alpha=.65$ ).

Behavioral Intentions. Behavioral intentions were partly adapted from Becker and Asbrock (2012). Active harm was assessed with eight items ("I verbally abuse /I could turn violent against /I insult members of / I engage actively against / search for confrontations with / I would sabotage... this group/I make fun of this group in front of others /I criticise this group in front of others", $\alpha=$ .87); passive harm was measured with four items ("I ignore /I don't pay attention to /I avoid contact with other members of / avoid conversations with other members of...this group", $\alpha=.82$ ); active facilitation was measured with five items ("I help / I assist members of / search for contact with / support ...this group/I try to facilitate this group's goals", $\alpha=.84$ ); passive facilitation was measured with two items ("I only search for contact with this group when it serves my own interests/ I only search for contact with this group if this fulfils a specific purpose", $\alpha=.77$ ); identity concealment was measured with two items ("I try to hide my membership in this group from others/I try to suppress all signs that convey my membership in this group", $\alpha=.84$ ). 
Results. Correlations between disidentification dimensions and all behavioral intentions are shown in Table 4. The variance inflation factors (VIF) for the three disidentification and five identification scales were below 10 (1.07-3.26), excluding the possibility of multicollinearity (for a critical discussion see O'Brien, 2007). To test whether the three disidentification components predicted negative ingroup-directed behavioral intentions and the intention to conceal one's identity, and whether the five identification components predicted positive ingroup-directed behaviors, we conducted a series of hierarchical regression analyses. These were followed up by mediation analyses to explore the role of emotions in explaining the links between disidentification and behavioral tendencies. In all mediation analyses, the disidentification and identification components were controlled for as covariates.

Active Harm. In the first step, we entered the five identification scales as a block; in the second step, we added the three disidentification scales as a block. In the first step, satisfaction was the only variable predicting active harm $(B=-.17, S E=.08, p=.03)$. Adding the disidentification scales to the model, $F(3,188)=4.30, \Delta R^{2}=.09, p<.01$, improved upon the prediction offered by the identification components alone, $F(5,191)=2.83, p=.02$. Results revealed that only detachment predicted active harm $(B=.21, S E=.08, p=.01)$. All other predictors were non-significant. Next, we tested whether the relation between detachment and active harm was mediated by negative emotions. Detachment predicted negative emotions $(B=.49, S E=.07, p<.001)$ and the total effect of detachment on active harm $(B=.27, S E=.08, p<.001)$ was reduced to a non-significant direct effect when negative emotions were included in the regression equation $(B=.003, S E=.07, p=.96)$, consistent with full mediation. Negative emotions $(B=.54, S E=.05, p<.001)$ were a reliable predictor of active harm in this model. A significant indirect effect of detachment via negative emotions was also confirmed using bootstrapping (e.g., Shrout \& Bolger, 2002; $B=.26, S E=.04, p<$ $.001,95 \% \mathrm{Cl}:[.18, .35])$.

Passive Harm. In the first step, solidarity $(B=-.26, S E=.10, p=.008)$ and homogeneity predicted passive harm $(B=.24, S E=.10, p=.001)$. Again, adding the disidentification scales into the 
model in the second step, $F(3,188)=13.19, \Delta R^{2}=.18 p<.001$, improved upon the prediction offered by the identification components alone, $F(5,191)=8.42, p<.001$. Results indicated that passive harm was predicted by detachment $(B=.42, S E=.09, p<.001)$, dissatisfaction $(B=.26, S E=.09, p<$ .01), but not dissimilarity. The only identification component that still predicted passive harm was homogeneity $(B=.16, S E=.06, p<.01)$. Next, we tested whether these effects were mediated by negative emotions. Only detachment and dissatisfaction predicted negative emotions $(B=.44, S E=$ $.07, p<.001 ; B=.29, S E=.07, p<.001$, respectively $)$, whereas homogeneity did not $(B=.06, S E=.06$, $p=.34)$. The positive relation between detachment and passive harm as well as between dissatisfaction and passive harm $(B=.44, S E=.09, p<.001 ; B=.27, S E=.09, p<.01$, respectively $)$ decreased when negative emotions were included in the regression equation $(B=.33, S E=.10, p<$ $.001 ; B=.21, S E=.09, p=.02$, respectively), indicating partial mediation. Negative emotions were a reliable predictor of passive harm $(B=.24, S E=.07, p=.001)$. Moreover, the indirect effects of detachment and dissatisfaction on passive harm via negative emotions were significant $(B=.10, S E=$ $.03, p=.002 ; B=.07, S E=.03, p=.008$, respectively) and the $95 \%$ confidence intervals of negative emotions excluded zero (95\% $\mathrm{Cl}:[.04, .17]$ and $[.02, .12]$, respectively).

Active facilitation. In the first step, solidarity $(B=.40, S E=.08, p<.001)$ and satisfaction predicted active facilitation $(B=.27, S E=.09, p=.002)$. Unexpectedly, adding the disidentification components in the second step in the model, $F(3,188)=15.63, \Delta R^{2}=.05, p<.001$, improved upon the prediction offered by the identification components alone, $F(5,191)=21.02, p<.001$. As expected, the strongest predictor of active facilitation was the identification component solidarity ( $B$ $=.37, S E=.07, p<.001)$. No other identification components were significant. Unexpectedly, however, detachment $(B=-.23, S E=.08, p<.01)$ and dissatisfaction $(B=-.16, S E=.08, p=.03)$ also contributed to the prediction of active facilitation. Thus, the more solidarity, the less detachment and the less dissatisfaction group members feel toward their group, the stronger their intention to actively help their group. As expected, the positive relation between solidarity and active facilitation $(B=.44, S E=.08, p<.001)$ decreased when positive emotions were included $(B=.32, S E=.07, p<$ 
.001). Moreover, the indirect effect of solidarity on active facilitation via positive emotions was significant $(B=.12, S E=.03, p<.001 ; 95 \% \mathrm{Cl}:[.05, .19])$. We explored whether the unexpected negative relations between detachment/dissatisfaction and active facilitation were also mediated by (a lack of) positive emotions. Indeed, the negative relation between detachment and active facilitation $(B=-.25, S E=.08, p=.002)$ as well as between dissatisfaction and active facilitation $(B=-$ $.23, S E=.08, p=.002)$ decreased when positive emotions were included $(B=-.19, S E=.08, p=.02 ; B$ $=-.14, S E=.07, p=.05)$. The indirect effects of detachment and dissatisfaction on active facilitation via positive emotions were significant $(B=-.06, S E=.02, p=.01 ; B=-.09, S E=.03, p=.001 ; 95 \% \mathrm{Cl}$ : [$.11,-.01]$ and $[-.14,-.04]$, respectively).

Passive Facilitation. Interestingly, none of the identification components predicted passive facilitation, $F(5,191)=1.68, p=.14$. However, adding the disidentification scales into the model in the second step led to a marginally significant prediction of passive facilitation, $F(3,188)=1.92, \Delta R^{2}=$ $.03, p=.06$. Detachment, but no other variable predicted passive facilitation $(B=.24, S E=.13, p=$ .05). We tested whether this relation was mediated by negative emotions. However, negative emotions did not predict passive facilitation $(B=.05, S E=.09, p=.62)$.

Identity Concealment. In the first step, satisfaction predicted identity concealment $(B=-.81$, $S E=.10, p<.001)$. Adding the disidentification scales in the second step, $F(3,189)=24.94, \Delta R^{2}=.21$, $p<.001$, improved upon the prediction that was offered by the identification components alone, $F(5,192)=16.47, p<.001$. Dissatisfaction and satisfaction (but the latter to a clearly lesser extend) predicted identity concealment $(B=.69, S E=.08, p<.001 ; B=-.22, S E=.11, p=.04)$. All other variables were not significant. We tested whether the relation between dissatisfaction and identity concealment was mediated by shame and guilt. Dissatisfaction predicted both shame $(B=.65, S E=$ $.07, p<.001)$ and guilt $(B=.25, S E=.08, p=.01)$. The relation between dissatisfaction and identity concealment $(B=.69, S E=.07, p<.001)$ was reduced when both emotions were included in the regression equation $(B=.45, S E=.08, p<.001)$ suggesting partial mediation. Shame $(B=.36, S E=$ $.06, p<.001)$ but not guilt $(B=-.001, S E=.05, p=.99)$ predicted identity concealment. A significant 
indirect effect of dissatisfaction via shame was also confirmed $(B=.24, S E=.05, p<.001,95 \% \mathrm{Cl}$ :

$[.15, .33])$. Satisfaction did not predict feelings of shame $(B=.09, S E=.12, p=.41)$ or guilt $(B=.13, S E$ $=.12, p=.30)$.

\section{Study $3 b$}

This study examined the relation between disidentification, emotions, and behavioral tendencies using additional measures collected as part of Study 2.

Method. Measures. Measures of emotions and behavioral intentions were the same as in Study 3a [active harm $(\alpha=.82)$, passive harm $(\alpha=.85)$, active facilitation $(\alpha=.89)$, passive facilitation $(\alpha=.63)$, identity concealment ( $\alpha=.93)$, positive emotions ( $\alpha=.78)$, negative emotions $(\alpha=.89)$, and shame $(\alpha=.91)]$.

Results. We tested whether disidentifiers differ from non-identifiers in terms of levels of active harm, passive harm, active facilitation, passive facilitation, and identity concealment, and examined the extent to which these differences were mediated by disidentification components in five separate regression analyses. We also again examined whether the relations between disidentification and behavioral tendencies were mediated by emotions. Because we included three experimental conditions in Study 2 (disidentification, nonidentification and identification), we created two dummy variables to compare the disidentification condition with both the nonidentification and identification conditions. The first dummy variable compared the nonidentification condition against the two other conditions (nonidentification $=1$, other $=0$ ). The second dummy variable compared the identification condition against the two other conditions (identification $=1$, all other $=0$ ). When both dummy variables are simultaneously entered into the regression equation, the nonidentification and identification conditions were compared with the zero-coded disidentification condition. As in Study 3a, we also controlled for the five identification components. Given our conceptual focus on distinguishing disidentification from nonidentification in Study 2, we do not report results of the mediational analyses regarding the less theoretically interesting comparison of the disidentification and identification condition here. The results for this 
comparison were almost identical to the results regarding the comparison of disidentification and nonidentification. Interested readers can obtain the results from the first author.

Active Harm. The first regression indicated that, as expected, disidentifiers (coded as 0 ) reported stronger intentions to actively harm their ingroup (see Table 5) compared to non-identifiers (coded as $1 ; B=-.49, S E=.19, p=.015$ ). When including the three disidentification and five identification components into the regression equation, the total effect between disidentification/nonidentification and active harm decreased to a non-significant direct effect $(B=-$ $.05, S E=.24, p=.84$ ), whereas detachment (but none of the other disidentification or identification components) was a reliable predictor of active harm $(B=.19, S E=.09, p=.03)$. The indirect effect of the manipulation on active harm via detachment was significant $(B=-.26, S E=.13, p=.04)$ and its 95\% confidence interval excluded zero (95\% $\mathrm{Cl}:[-.01,-.52])$.

In order to replicate the results of Study 3a, we tested if the relation between detachment and active harm was mediated by negative emotions. Results show that the total effect of the relation between detachment and active harm $(B=.24, S E=.07, p<.001)$ was reduced to a nonsignificant direct effect when negative emotions were included $(B=.04, S E=.06, p=.42)$. The indirect effect of detachment on active harm via negative emotions was significant $(B=-.44, S E=$ $.15, p=.004)$ and its $95 \%$ confidence interval excluded zero $[.11, .28]$. Moreover, the full chain of mediation (nonidentification vs. disidentification $\rightarrow$ detachment $\rightarrow$ negative emotions $\rightarrow$ active harm) was significant $(B=-.28, S E=.09, p=.002 ; 95 \% \mathrm{Cl}:[-.10,-.46])$.

Passive Harm. The second regression indicated that as expected participants in the disidentification condition reported a stronger intention to passively harm their ingroup (see Table 5) compared to participants in the nonidentification condition $(B=-.82, S E=.29, p=.005)$. When we included the three disidentification and five identification components, the total effect of the manipulation on passive harm decreased to a non-significant direct effect $(B=-.18, S E=.30, p=.55)$, whereas detachment (but no other variable) was a reliable predictor of passive harm $(B=-.22, S E=$ $.10, p=.03)$. The indirect effect of the manipulation on passive harm via detachment was significant 
$(B=-.40, S E=.17, p=.02 ; 95 \% \mathrm{Cl}:[-.07,-.74])$. Finally, we tested whether the relation between detachment and passive harm was mediated by negative emotions. Results show that the total effect of the relation between detachment and passive harm $(B=.31, S E=.10, p=.002)$ was reduced when negative emotions were included $(B=.23, S E=.10, p=.02)$. The indirect effect of detachment on passive harm via negative emotions was significant $(B=.08, S E=.04, p=.03,95 \% \mathrm{Cl}$ : $.01, .15]$ ). Moreover, the full chain of mediation (nonidentification vs. disidentification $\rightarrow$ detachment $\rightarrow$ negative emotions $\rightarrow$ passive harm $)$ approached significance $(B=-.11, S E=.06, p=$ $.058 ; 95 \% \mathrm{Cl}:[-.004, .22])$.

Active Facilitation. Disidentifiers reported a lower intention of active facilitation compared to non-identifiers ( $B=.78, S E=.34, p=.02$, see Table 5$)$. Only the identification component solidarity $(B=.51, S E=.09, p<.001)$ predicted active facilitation. However, the disidentification/nonidentification dummy did not predict solidarity $(B=-.51, S E=.34, p=.14)$. Finally, we tested whether the relation between solidarity and active facilitation was mediated by positive emotions. Results show that the total effect of the relation between solidarity and active facilitation $(B=.59, S E=.09, p<.001)$ was reduced when positive emotions were included $(B=.45$, $S E=.09, p<.001)$. The indirect effect of solidarity on active facilitation via positive emotions was significant $(B=.14, S E=.06, p=.02,95 \% \mathrm{Cl}: .02, .25])$.

Passive Facilitation. Disidentifiers reported a higher passive facilitation intentions compared to non-identifiers $(B=-1.15, S E=.39, p=.004$, see Table 5$)$. When including the three disidentification and five identification components, the total effect between disidentification/nonidentification and passive facilitation decreased to a non-significant direct effect $(B=-.46, S E=.50, p=.37)$. Detachment (but none of the other disidentification or identification components) emerged as a reliable predictor of passive facilitation $(B=.37, S E=.18, p$ $=.04)$. The indirect effect of the manipulation on passive facilitation via detachment was significant $(B=.56, S E=.28, p=.046 ; 95 \% \mathrm{Cl}:[-.01,-1.12])$. Next, we tested whether the relation between detachment and passive harm was mediated by negative emotions. However, as before, when 
controlling for all identification and disidentification components, negative emotions did not predict passive facilitation $(B=-.12, S E=.18, p=.50)$.

Identity Concealment. Finally, as expected, disidentifiers reported stronger intentions to conceal their group membership compared to non-identifiers $(B=-1.67, S E=.39, p<.001$, see Table 5). When including the three disidentification and five identification components, the total effect between disidentification/nonidentification and identity concealment decreased to a non-significant direct effect $(B=.21, S E=.38, p=.58)$, whereas dissatisfaction emerged as a reliable predictor of identity concealment $(B=.67, S E=.13, p<.001)$. Satisfaction was also a predictor of identity concealment $(B=-.33, S E=.15, p=.03)$. The indirect effect of the manipulation on identity concealment via dissatisfaction was significant $(B=1.60, S E=.37, p<.001 ; 95 \% \mathrm{Cl}:[-.88,-2.32])$. Again, we tested the extent to which the relation between dissatisfaction and identity concealment was mediated by shame. Results showed that the total effect of the relation between dissatisfaction and identity concealment $(B=.71, S E=.12, p<.001)$ was reduced when shame was included $(B=$ $.48, S E=.13, p<.001)$. The indirect effect of dissatisfaction on identity concealment via shame was significant $(B=.23, S E=.07, p=.002,95 \% \mathrm{Cl}:[.08, .37])$. Moreover, the full chain of mediation (nonidentification vs. disidentification $\rightarrow$ dissatisfaction $\rightarrow$ shame $\rightarrow$ concealment) was significant ( $B$ $=-.53, S E=.19, p=.004 ; 95 \% \mathrm{Cl}:[-.17,-.90])$.

Discussion. This study illustrated the value of the multi-component disidentification scale by systematically examining the predictive power of disidentification components on behavioral intentions, over and above established measures of identification. We demonstrated that disidentification is not merely the opposing pole of identification but that the two constructs predict different outcomes. Additionally, we provided first evidence for the emotional processes that may be involved. As expected, the disidentification scales predicted negative behavioral intentions better than the identification scales, whereas the identification scales (in particular solidarity) predicted positive behavioral intentions better than the disidentification scales. This finding implies that the identification and disidentification components do not just have opposing effects on outcome 
variables. Instead, disidentification uniquely predicted active harm, passive harm, passive facilitation and identity concealment, whereas identification did not. This finding strengthens the necessity of the construct of disidentification and is in line with other two-dimensional constructs developed in psychological research (e.g., Cacioppo et al., 1997; Elliot et al., 2006; Gable \& Strachman, 2008; Sassenberg et al., 2003; Watson et al., 1988). Detachment and dissatisfaction turned out to be the best predictors of all five behavioral intentions, whereas dissimilarity played only a minor role. In Study $3 a$ and $3 b$, detachment positively predicted active harm, passive harm and passive facilitation. This implies that a psychological distance from one's ingroup (detachment) is associated with different types of negative ingroup-directed behaviors. Moreover, negative ingroup-directed emotions accounted for the relations between detachment and active and passive harm. In contrast, dissatisfaction (but not detachment) consistently predicted intentions to conceal one's group membership and this relation was mediated by feelings of shame about belonging to the group. Thus, detachment and dissatisfaction are associated with different emotions and behavioral intentions: whereas detachment is associated with feelings of anger and contempt that in turn predict aggressive behavioral tendencies directed at the ingroup, dissatisfaction is associated with feelings of shame and predicts intentions to conceal one's group membership. However, in Study 3a (but not in Study 3b), dissatisfaction also predicted milder forms of harm, namely passive harm and a lack of active facilitation. Thus, dissatisfaction is also associated with intentions to avoid other group members and intentions to refuse to help one's ingroup.

Whereas dissimilarity was positively correlated with active and passive harm, it did not predict these variables when controlling for detachment and dissatisfaction. This is not surprising, as feeling detached and alienated from one's group seems to be a stronger motivator to harm one's ingroup compared to just feeling dissimilar compared to other group members. Finally, against expectations, detachment and dissimilarity predicted active facilitation in Study 3a. However, this effect did not replicate in Study 3b. 
Taken together, results of both studies support our prediction that the disidentification components work particularly well (and were more useful than the identification components) in predicting negative ingroup-directed behavioral intentions, whereas the identification components (particularly solidarity) are useful in predicting positive ingroup-directed behavioral intentions.

\section{General Discussion}

The present research contributes to the literature on disidentification in several important ways. First, it advances theory and measurement of disidentification by introducing a multicomponent model of disidentification. Previous approaches to measure disidentification conceptualized it as a one-dimensional construct, which nevertheless included aspects that tapped different dimensions of disidentification, or confounded disidentification with attitudes, specific emotions and behavioral intentions. Thus, so far it was unclear which aspects of disidentification were measured with previous scales and whether disidentification is separable from other psychological variables (i.e., attitudes, specific emotions, behavioral intentions). By proposing a three-component model of ingroup disidentification our approach provides a more thorough and nuanced understanding of the nature of disidentification. Second, the present research extends previous research by demonstrating that disidentification scales work better than identification scales in differentiating between disidentification and nonidentification. This shows that disidentification is different from nonidentification and points to the viability and usefulness of the multi-dimensional model of disidentification. Third, by differentiating the three components of disidentification from attitudes, specific emotions and behavioral intentions, our approach allowed a more detailed analysis of behavioral and emotional correlates of ingroup disidentification. An examination of five different types of ingroup- and self-directed behaviors (compared to, for instance, a single behavior such as avoiding the group) enabled us to examine how the three disidentification components predicted various types of behavioral tendencies. By demonstrating how disidentification predicts negative emotions and negative ingroup-directed behavioral intentions (whereas identification did not), we illustrated how disidentification contributes to our 
knowledge about social psychological processes above and beyond identification. Finally, we believe that the brief three-component measure may be widely applicable for examining disidentification from a variety of groups in different cultural and language contexts.

\section{The Concept of Disidentification}

In line with conceptualizations of social identity (Tajfel, 1981) and in parallel to research on social identification (e.g., Ellemers et al., 1999), we suggested that disidentification manifests itself along the three dimensions of detachment, dissatisfaction, and dissimilarity. Our three-component model was supported in confirmatory factor analyses using one English-speaking and one Germanspeaking sample. Alternative models, such as a single-factor model or a disidentification approach based on two components fit the data less well. Moreover, although most of the disidentification components were negatively related to ingroup identification, a CFA revealed that a model with separate identification and disidentification components fit the data better than a model in which identification and disidentification components load together. This supports the idea that the disidentification components are unique and separate from identification.

Furthermore, we provided evidence that disidentification components were either unrelated to, or only weakly to moderately correlated with related concepts such as stigma consciousness (Pinel, 1999), public collective self-esteem as well as personal self-esteem (Luhtanen \& Crocker, 1992; Rosenberg, 1965). We also provided evidence that disidentification and nonidentification are distinguishable (see also Ikegami, 2010). Results revealed that disidentifiers scored significantly higher on the three disidentification components compared to non-identifiers. However, disidentifiers were not distinguishable from non-identifiers in terms of the three identification scales solidarity, centrality, and dissimilarity. This indicates that low scores on identification scales cannot be equaled with disidentification. Thus, we suggest that it would be more precise to use scales designed to measure disidentification (e.g., when examining disidentification by means of a longitudinal analysis) rather than subtracting identification scores at different times of measurement as an indicator of disidentification. 


\section{Emotions and Behavioral Tendencies as Correlates of Disidentification}

We further examined the relations between disidentification and ingroup-directed behavioral intentions (active and passive harm, active and passive facilitation; Cuddy et al., 2007) and the intention to conceal one's group membership. By doing so, the present research advances our understanding of the likely behavioral consequences of disidentification. Moreover, we provide first evidence that the different disidentification components are related to different behavioral intentions. Regression analyses revealed that detachment and dissatisfaction are particularly predictive of behavioral intentions. For example, results of Study 3a and Study 3b consistently showed that detachment was uniquely associated with tendencies to avoid the ingroup (passive harm), attack the ingroup (active harm) and to use it for egoistic purposes (passive facilitation). Dissatisfaction, in contrast, was shown to have a unique association with intentions to conceal one's group membership (in Study 3a and Study 3b) and to avoid one's group (passive harm) in Study 3a. Overall, results supported the expectation that disidentification components are better in predicting harming behavioral intentions than helping behavioral intentions, whereas identification components (particularly solidarity) are better in predicting helping than harming behavioral intentions. These findings illustrate that disidentification is not merely the opposite of identification but that disidentification and identification represent two separate constructs with distinct consequences. This is in line with research showing that several seemingly bipolar psychological concepts are in fact made up of two separate dimensions with different psychological correlates and outcomes (e.g., Cacioppo et al., 1997; Gable \& Strachman, 2008; Sassenberg et al., 2003; Watson et al., 1988). Group-level emotions played a crucial role in translating manifestations of disidentification into ingroup-directed behavioral tendencies. We demonstrated that negative emotions consistently accounted for the relation between detachment and both active and passive harm, whereas shame was most important in explaining the link between dissatisfaction and identity concealment. In sum, it seems that different facets of disidentification are differentially related to specific emotional responses to the ingroup and consequently to specific behavioral orientations. It 
is worth noting that detachment was the most important component in predicting negative ingroupdirected behavioral intentions and was also most strongly related to our pictorial measure "inclusion-exclusion of the ingroup from the self". This finding provides further evidence for the usefulness of our newly constructed disidentification scale given that most of the prior disidentification scales did not measure detachment. However, due to the correlational nature of our data, these conclusions are preliminary and should be considered with caution. Future research is necessary to manipulate the presence of the three components of disidentification to investigate their causal effects on group-level emotions and behaviors.

\section{Directions for Future Research}

Future research should provide systematic tests of the predictors of detachment, dissatisfaction and dissimilarity. Disidentification can be triggered by feelings of rejection (e.g., Jasinskaja-Lahti et al., 2009; Verkuyten \& Yildiz, 2007, but see Matschke \& Sassenberg, 2010), a lack of ingroup support (Becker et al., 2011), a perceived conflict of values between oneself and the group (Elsbach \& Battacharya, 2001; Glasford et al., 2008), a negative reputation of the group (Kreiner \& Ashforth, 2004), stigma-based discrimination (e.g., Jasinskaja-Lahti et al., 2009; Verkuyten \& Yildiz, 2007) or categorization threat (Barreto \& Ellemers, 2003; Branscombe, Ellemers, Spears, \&, \& Doosje, 1999). Given that most of this prior research used one-dimensional measures of disidentification, it would be intriguing to examine whether and how these antecedents are differentially related to the three components of ingroup disidentification. For instance, it is conceivable that a lack of ingroup support predicts detachment, because this non-support is clearly threatening and likely to trigger feelings of alienation and psychological distance. Moreover, a perceived conflict of values may predict dissimilarity and detachment. Particularly a moral conflict with the ingroup may lead individuals to realize that they have less in common with other group members or are in fact direct opposites. Such a perception should motivate individuals to separate themselves from their ingroup. Finally, it is likely that experienced rejection, stigma-based 
discrimination and a negative reputation of one's ingroup may predict dissatisfaction, because these experiences express a negative evaluation of the ingroup.

Moreover, there are likely to be a range of group characteristics that impact on, or interact with, disidentification and thus warrant further study. For instance, it would improve our understanding of the concept if we knew whether the nature of disidentification differs depending on whether individuals disidentify from low status groups (e.g., social stigma) or high status groups (e.g., upper social class). Furthermore, disidentification should manifest itself differently depending on whether group membership is unavoidable (e.g., being black/white) versus potentially avoidable (e.g., being heavyweight, being unemployed) or when one belongs to a group by association (e.g., the regional or family background). Furthermore, it would be interesting to study disidentification among individuals with conspicuous stigma (e.g., being heavyweight) versus concealable stigma (e.g., poverty).

\section{Conclusion}

In conclusion, the present research shows how the concept of disidentification can be defined, how it is likely to manifest itself and how it can be measured. We distinguished the three components detachment, dissatisfaction and dissimilarity and developed a measurement scale that assesses these elements. Furthermore, we demonstrated the unique value of the concept of disidentification by showing how disidentification can be distinguished from nonidentification and by illustrating the unique emotional and behavioral correlates of disidentification. Taken together, our results demonstrate that the concept of disidentification contributes to our knowledge about social psychological processes above and beyond identification. 


\section{References}

Barreto, M., \& Ellemers, N. (2003). The effects of being categorised: The interplay between internal and external social identities. In W. Stroebe \& M. Hewstone (Eds.), European Review of Social Psychology (Vol. 14, pp. 139-170). Chichester: Wiley.

Barreto, M., Ellemers, N., \& Banal, S. (2006). Working under cover: Performance-related selfconfidence among members of contextually devalued groups who try to pass. European Journal of Social Psychology, 36, 337-352.

Becker, J.C., \& Asbrock, F. (2012). What triggers helping versus harming of ambivalent groups? Effects of the relative salience of warmth versus competence. Journal of Experimental Social Psychology, 48, 19-27.

Becker, J.C., Tausch, N., Spears, R., \& Christ, O. (2011). Committed dis(s)idents: Participation in radical collective action fosters disidentification with the broader in-group but enhances political identification. Personality and Social Psychology Bulletin, 37, 1104-1116.

Branscombe, N. R., Ellemers, N., Spears, R., \& Doosje, B. (1999). The context and content of social identity threats. In N. Ellemers, R. Spears, \& B. Doosje (Eds.), Social identity: Context, commitment, and content (pp. 35-58). Oxford, UK: Blackwell.

Branscombe, N., Fernandez, S., Gómez, A., \& Cronin, T. (2011).Moving toward or away from a group identity: Different strategies for coping with pervasive discrimination. In J. Jetten, C. Haslam, \& A. Haslam (Eds.) The Social Cure: Identity, Health and Well-Being (pp. 115-132). New York: Psychology Press.

Brewer, M. B. (2001). Ingroup identification and intergroup conflict: When does ingroup love become outgroup hate? In R. Ashmore, L. Jussim, \& D. Wilder (Eds.), Social identity, intergroup conflict, and conflict reduction (p. 2-41). New York: Oxford University Press.

Cacioppo, J. T., Gardner, W. L., \& Berntson, G. G. (1997). Beyond bipolar conceptualizations and measures: The case of attitudes and evaluative space. Personality and Social Psychology Review, 1, 3-25. 
Cameron, J. (2004). A three-component model of social identification. Self and Identity, 3, 239-262.

Crocker, J., Major, B., \& Steele, C. (1998). Social stigma. In Gilbert, D., Fiske, S. T., \& Lindzey, G. (Eds.), The Handbook of Social Psychology (4th ed., Vol. 2, pp. 504-553). New York: McGraw Hill.

Cuddy, A. J. C., Fiske, S. T., \& Glick, P. (2007). The BIAS map: Behaviors form intergroup affect and stereotypes. Journal of Personality and Social Psychology, 92, 631-648.

Dean, J. (2008). The lady doth protest too much: theorizing disidentification in contemporary gender politics. Ideology in Discourse Analysis, 24, 1-19.

Ellemers, N., Kortekaas, P., \& Ouwerkerk, J. W. (1999). Selfcategorisation, commitment to the group and group self-esteem as related but distinct aspects of social identity. European Journal of Social Psychology, 29, 371-389.

Ellemers, N., Van Den Heuvel, H., De Gilder, D., Maass, A., \& Bonvini, A. (2004). The underrepresentation of women in science: Differential commitment or the queen bee syndrome? British Journal of Social Psychology, 43, 315-338.

Elliot, A. J., Gable, S. L., \& Mapes, R. R. (2006). Approach and avoidance motivation in the social domain. Personality and Social Psychology Bulletin, 32, 378-391.

Elsbach, K. (1999). An expanded model of organizational identification. Research in Organizational Behaviour, 21, 163-200.

Elsbach, K. D., \& Bhattacharya, C. B. (2001). Defining who you are by what you're not: Organizational disidentification and the National Rifle Association. Organizational Science, 12, 393-413.

Gable, S. L. (2006). Approach and avoidance social motives and goals. Journal of Personality, 74, $175-222$.

Gable, S. L., \& Strachman, A. (2008). Approaching social rewards and avoiding social punishments: Appetitive and aversive social motivation. In J. Y. Shah, \& W. L. Gardner (Eds.), Handbook of motivation science (pp. 561-575). New York: Guilford Press.

Glasford, D.E., Pratto, F., \& Dovidio, J.F. (2008). Intragroup dissonance: Responses to ingroup violation of personal values. Journal of Experimental Social Psychology, 44, 1057-1064. 
Herzog, W., Boomsma, A., \& Reinecke, S. (2007). The model-size effect on traditional and modified tests of covariance structures. Structural Equation Modeling, 14, 361-390.

Hu, L.T., \& Bentler, P.M. (1999). Cutoff criteria for fit indexes in covariance structure analysis: conventional criteria versus new alternatives. Structural Equation Modeling, 6, 1-55. Ikegami, T. (2010) Precursors and consequences of ingroup disidentification: Status system beliefs and social identity. Identity: An International Journal of Theory and Research, 10, 233-253. Ikegami, T., \& Ischida, Y. (2007). Status hierarchy and the role of disidentification in discriminatory perception of outgroups. Japanese Psychological Research, 49, 136-147.

Jackson, J. W. (2002). Intergroup attitudes as a function of different dimensions of group identification and perceived intergroup conflict. Self and Identity, 1, 11-33.

Jasinskaja-Lahti, I., Liebkind, K., \& Solheim, E. (2009). To identify or not to identify? National disidentification as an alternative reaction to perceived ethnic discrimination. Applied Psychology, 58, 105-128.

Josiassen, A. (2011). Consumer disidentification and its effects on domestic product purchases: An empirical investigation in the Netherlands. Journal of Marketing, 75, 124-140.

Kreiner, G. E., \& Ashforth, B. E. (2004). Evidence toward an expanded model of organizational identification. Journal of Organizational Behavior, 25, 1-27.

Leach, C.W., van Zomeren, M., Zebel, S., Vliek, M.L.W., Pennekamp, S.F., Doosje, B., Ouwerkerk, J.W., \& Spears, R. (2008). Group-level self-definition and self-investment: A hierarchical (multi-component) model of in-group identification. Journal of Personality and Social Psychology, 95, 144-165.

Levin, S., \& Van Laar, C. (Eds.) (2006). Stigma and group inequality: Social psychological approaches. Lawrence Erlbaum.

Long, K., \& Spears, R. (1997). The self-esteem hypothesis revisited: Differentiation and the disaffected. In R. Spears, P. J. Oakes, N. Ellemers, \& S. A. Haslam (Eds), The social psychology of stereotyping and group life (pp. 296 \pm 317$)$ ). Oxford: Blackwell. 
Luhtanen, R., \& Crocker, J. (1992). A collective self-esteem scale: Self-evaluation of one's social identity. Personality and Social Psychology Bulletin, 18, 302-318.

Major, B. \& O'Brien, L.T. (2005). The social psychology of stigma. Annual Review of Psychology, 56, 393-421.

Matschke, C., \& Sassenberg, K. (2010a). Does rejection lead to disidentification? The role of internal motivation and avoidance strategies. European Journal of Social Psychology, 40, 891-900.

Matschke, C., \& Sassenberg, K. (2010b). The supporting and impeding effects of group-related approach and avoidance strategies on newcomers' psychological adaptation. International Journal of Intercultural Relations, 34, 465-474.

Muthén, L.K., \& Muthén, B.O. (2002). Mplus User's Guide. Los Angeles, CA: Muthén \& Muthén.

O'Brien, R.M. (2007). A Caution Regarding Rules of Thumb for Variance Inflation Factors. Quality and Quantity, 41, 673-690.

Pinel, E. C. (1999). Stigma consciousness: The psychological legacy of social stereotypes. Journal of Personality and Social Psychology, 76, 114-128.

Quinn, D.M. (2006). Concealable versus conspicuous stigmatized identities. In S. Levin \& C. van Laar (eds). Stigma and group inequality (pp. 83-104). Mahwah: Lawrence Erlbaum Associates.

Rosenberg, M.J. (1965). Society and the adolescent self-image. Princeton, NJ: Princeton University Press.

Satorra, A., \& Bentler, P.M. (2001). A scaled difference chi-square test statistic for moment structure analysis. Psychometrika, 66, 507-514.

Sassenberg, K., Kessler, T. \& Mummendey, A. (2003). Less negative = more positive? Social discrimination as avoidance and approach. Journal of Experimental Social Psychology, 39, 4858.

Schubert, T., \& Otten, S. (2002). Overlap of self, ingroup and outgroup: Pictorial measurement of self-categorization. Self and Identity, 4, 353-376. 
Shrout, P. E., \& Bolger, N. (2002). Mediation in experimental and nonexperimental studies: New procedures and recommendations. Psychological Methods, 7, 422-445.

Swann, W. B., Jr., Gómez, A., Seyle, C., Morales, F., \& Huici, C. (2009). Identity fusion: The interplay of personal and social identities in extreme group behavior. Journal of Personality and Social Psychology, 96, 995-1011.

Tajfel, H. (1974). Social identity and intergroup behaviour. Social Science Information, 13, 65-93.

Tajfel, H. (1981). Human groups and social categories. Cambridge: Cambridge University Press.

Tajfel, H., \& Turner, J. C. (1979). An integrative theory of intergroup conflict. In W. G. Austin, \& S. Worchel (Eds.), The social psychology of intergroup relations. (pp. 33-48). Monterey, CA: Brooks/Cole.

Tropp, L. R., \& Wright, S. C. (2001). Ingroup identification as inclusion of ingroup in the self. Personality and Social Psychology Bulletin, 27, 585-600.

Turner, J. C., Hogg, M. A., Oakes, P. J., Reicher, S. D., \& Wetherell, M. S. (1987). Rediscovering the social group: A self-categorization theory. Cambridge, MA: Blackwell.

Verkuyten, M. \&. Yildiz, A.A. (2007). National (Dis)identification and Ethnic and Religious Identity: A Study Among Turkish-Dutch Muslims. Personality and Social Psychology Bulletin, 33, 144862.

Watson, D., Clark, L. A., \& Tellegen, A. (1988). Development and validation of brief measures of positive and negative affect: The PANAS scales. Journal of Personality and Social Psychology, $54,1063-1070$.

Wright, S. C., \& Taylor , D. M. (1998). Responding to tokenism: Individual action in the face of collective injustice. European Journal of Social Psychology, 28, 647-667.

Zou, X., Morris, M. W., \& Benet-Martinez, V. (2008). Identity motives and cultural priming: Cultural (dis)identification in assimilative and contrastive responses. Journal of Experimental Social Psychology, 44, 1151-1159. 
Table 1

Fit Indices Study 1a $(N=168)$ before the slash and Study $1 \mathrm{~b}(N=215)$ after the slash

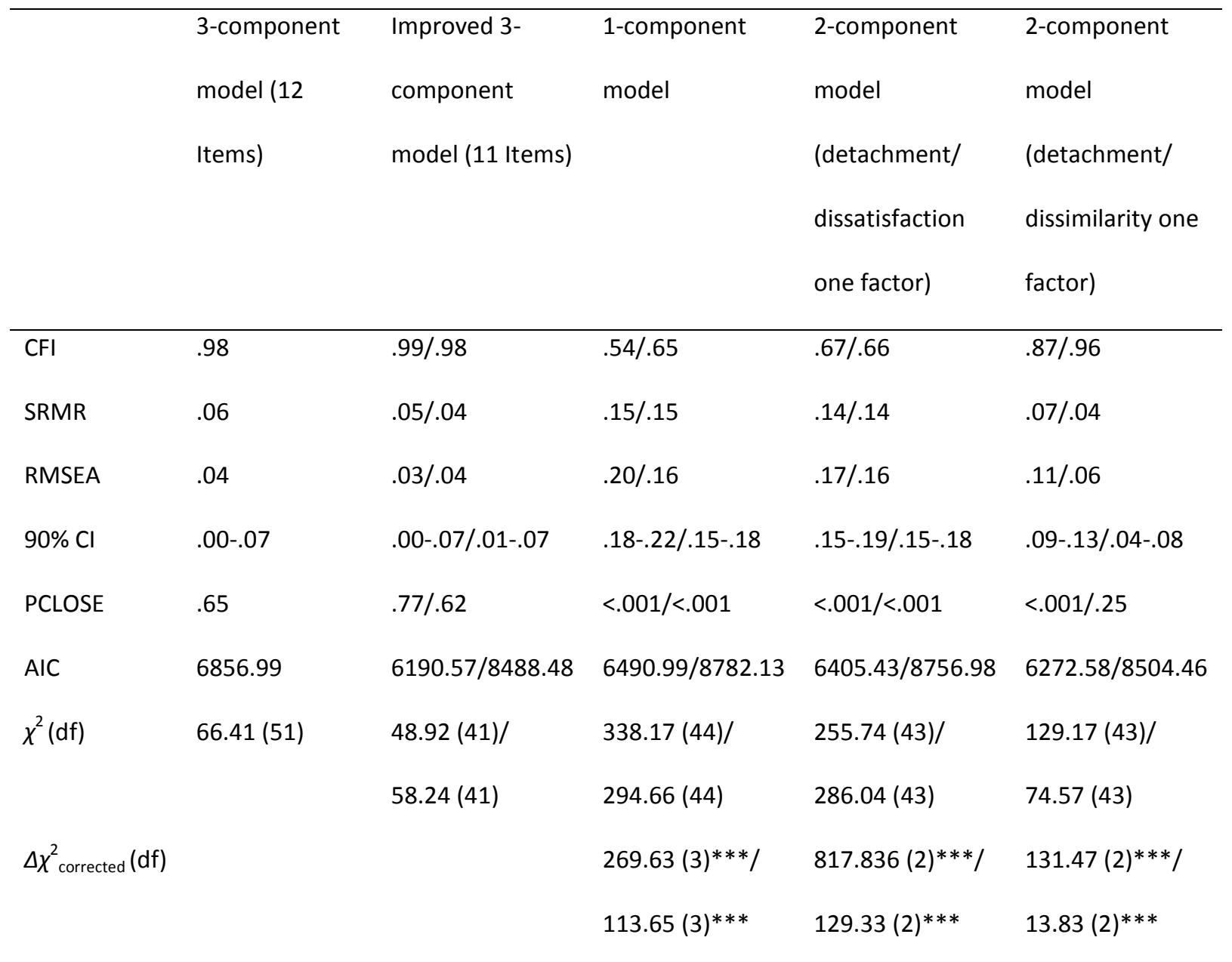

Note. The first 3-component model is based on 12 items, all other model are based on 11 items (one item measuring detachment was excluded). We used the chi-square difference test using the Satorra-Bentler scaled chi-square (Sartorra-Bentler, 2001). We compared each alternative model with the improved 3-component model; ${ }^{* * *} p<.001$ 
Table 2

Correlations among disidentification, identification components, and individual ingroup distance, Study 1a (before the slash, $N=168$ ) and Study $1 b$ (after the slash, $N=215)$ )

\begin{tabular}{|c|c|c|c|c|}
\hline & Detachment & Dissatisfaction & Dissimilarity & $\begin{array}{c}\text { Exclusion of } \\
\text { ingroup from the } \\
\text { self }\end{array}$ \\
\hline Detachment & 1 & $.29 * * / .17 *$ & $.56 * * / .68 * *$ & $.51 * * / .49 * *$ \\
\hline Dissatisfaction & $.29 * * / .17 *$ & 1 & $.22^{* *} / .12^{+}$ & $.25^{* *} / .13^{+}$ \\
\hline Dissimilarity & $.56 * * / .68 * *$ & $.22 * * / .12^{+}$ & 1 & $.38 * * / .44 * *$ \\
\hline Solidarity & $-.45 * * /-.32 * *$ & $-.51 * * /-.30 * *$ & $-.37 * * /-.39 * *$ & $-.35 * * /-.39 * *$ \\
\hline Satisfaction & $-.30 * * /-.16 *$ & $-.68^{* *} /-.65^{* *}$ & $-.33 * * /-.22 * *$ & $-.31 * * /-.25 * *$ \\
\hline Centrality & $-.30 * * /-.32 * *$ & $-.26 * * /-.13^{+}$ & $-.30 * * /-.33 * *$ & $-.31 * * /-.25 * *$ \\
\hline Self-Stereotyping & $-.46 * * /-.44 * *$ & $-.06 /-.02$ & $-.64 * * /-.66 * *$ & $-.33 * * /-.46 * *$ \\
\hline Homogeneity & $-.02 / .07$ & $.03 / .01$ & $0 / .05$ & $0 / 0$ \\
\hline
\end{tabular}


Table 3

Means and standard deviations of disidentification and identification components as a function of condition, Study $2(N=115)$

\begin{tabular}{lccc}
\hline & Disidentification & Nonidentification & Identification \\
\hline Detachment & $4.24(1.68)_{\mathrm{a}}$ & $2.82(1.44)_{\mathrm{b}}$ & $1.83(1.06)_{\mathrm{c}}$ \\
Dissatisfaction & $4.49(1.70)_{\mathrm{a}}$ & $2.11(1.38)_{\mathrm{b}}$ & $1.38(.56)_{\mathrm{c}}$ \\
Dissimilarity & $4.38(1.61)_{\mathrm{a}}$ & $3.51(1.28)_{\mathrm{b}}$ & $2.51(1.19)_{\mathrm{c}}$ \\
Solidarity & $2.93(1.65)_{\mathrm{a}}$ & $3.44(1.22)_{\mathrm{a}}$ & $5.26(1.32)_{\mathrm{c}}$ \\
Satisfaction & $2.57(1.46)_{\mathrm{a}}$ & $3.88(1.45)_{\mathrm{b}}$ & $5.99(.88)_{\mathrm{c}}$ \\
Centrality & $3.10(1.60)_{\mathrm{a}}$ & $3.13(1.40)_{\mathrm{a}}$ & $5.12(1.24)_{\mathrm{b}}$ \\
Self-stereotyping & $2.90(1.67)_{\mathrm{a}}$ & $3.10(1.15)_{\mathrm{a}}$ & $4.41(1.45)_{\mathrm{c}}$ \\
Homogeneity & $4.03(1.50)_{\mathrm{a}}$ & $3.14(1.09)_{\mathrm{b}}$ & $4.35(1.30)_{\mathrm{a}}$ \\
\hline
\end{tabular}

Note: Across row means not sharing subscripts differ at $p<.05$ (Tukey) 
Table 4

Correlations among disidentification scales and behavioral intentions, Study $3 a(N=215)$

\begin{tabular}{lccccc}
\hline & Active Harm & Passive Harm & Active & Passive & Identity \\
& & & Facilitation & Facilitation & Concealment \\
\hline Detachment & $.36^{* *}$ & $.51^{* *}$ & $-.36^{* *}$ & $.15^{*}$ & .09 \\
Dissatisfaction & .05 & $.32^{* *}$ & $-.39^{* *}$ & $-.12^{+}$ & $.71^{* *}$ \\
Dissimilarity & $.32^{* *}$ & $.40^{* *}$ & $-.28^{* *}$ & .09 & .10 \\
\hline
\end{tabular}

Note: ${ }^{* *} p<.01,{ }^{*} p<.05,{ }^{+} p<.10$ 
Table 5

Means and standard deviations of behavioral intentions as a function of condition, Study $3 \mathrm{~b}(N=$ 115)

\begin{tabular}{lcc}
\hline & Disidentification & Nonidentification \\
\hline Active harm & $1.95(1.07)_{\mathrm{a}}$ & $1.46(.68)_{\mathrm{b}}$ \\
Passive harm & $2.77(1.55)_{\mathrm{a}}$ & $1.94(1.23)_{\mathrm{b}}$ \\
Active facilitation & $3.60(1.63)_{\mathrm{a}}$ & $4.38(1.37)_{\mathrm{b}}$ \\
Passive facilitation & $4.15(1.71)_{\mathrm{a}}$ & $3.00(1.59)_{\mathrm{b}}$ \\
Identity Concealment & $3.52(2.18)_{\mathrm{a}}$ & $1.84(1.48)_{\mathrm{b}}$ \\
\hline Note: Across row means not sharing subscripts differ at $p<.05$ (Tukey)
\end{tabular}




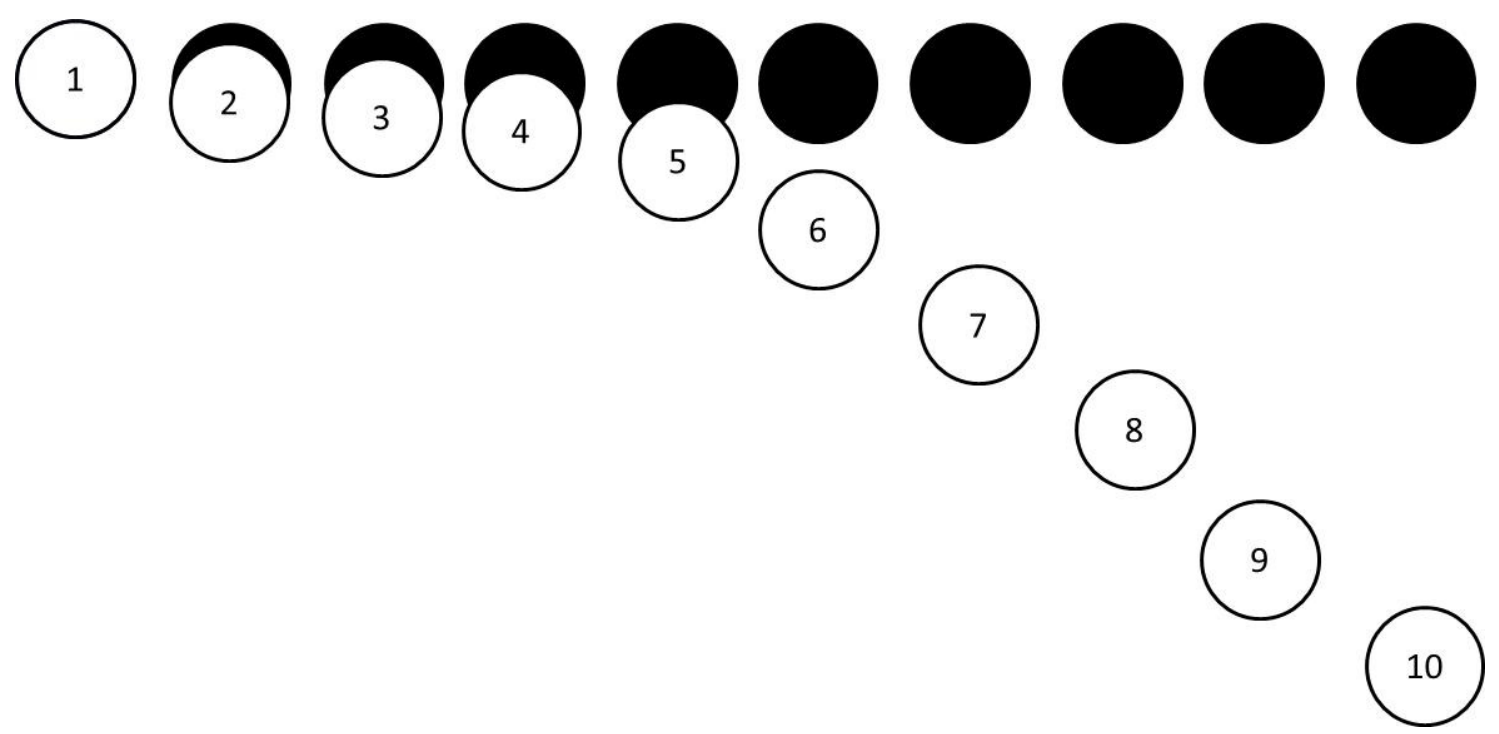

Figure 1. "Inclusion-Exclusion of the group from the self" measure 
Appendix: Three-component measure of disidentification (Factor loadings Study 1a/1b and German translation in brackets)

Detachment

I feel a distance between myself and this group (.77/.75). (Ich habe ein distanziertes Verhältnis zu dieser Gruppe.)

I feel detached from this group (.90/.66). (Ich fühle mich von dieser Gruppe abgesondert.) I feel alienated from this group (.72/.69). (Ich fühle mich von dieser Gruppe entfremdet.) I feel disloyal to this group (.36/.53). (Ich bin gegenüber dieser Gruppe nicht loyal. This item was excluded)

\section{Dissatisfaction}

I'm unhappy about being a member of this group (.77/.67). (Ich bin unglücklich darüber, dass ich dieser Gruppe angehöre.)

I regret that I belong to this group (.80/.76). (Ich bedaure, dass ich dieser Gruppe angehöre.) I wish I had nothing to do with this group (.78/.71). (Ich wünschte, ich hätte mit dieser Gruppe nichts zu tun.)

Being in this group gives me a bad feeling (.68/.79). (In dieser Gruppe zu sein gibt mir ein schlechtes Gefühl.)

\section{Dissimilarity}

I have nothing in common with most members of this group (.70/.89). (Mit den meisten Personen aus dieser Gruppe habe ich nichts gemeinsam.)

I'm dissimilar to the average person of this group (.72/.69). (Ich bin der durchschnittlichen Person dieser Gruppe unähnlich)

I'm completely different from other members of this group (.81/.78). (Ich bin ganz anders als die meisten Mitglieder dieser Gruppe.)

I'm the opposite of people in this group (.72/.69). (Ich bin das Gegenteil von Personen in dieser Gruppe.) 